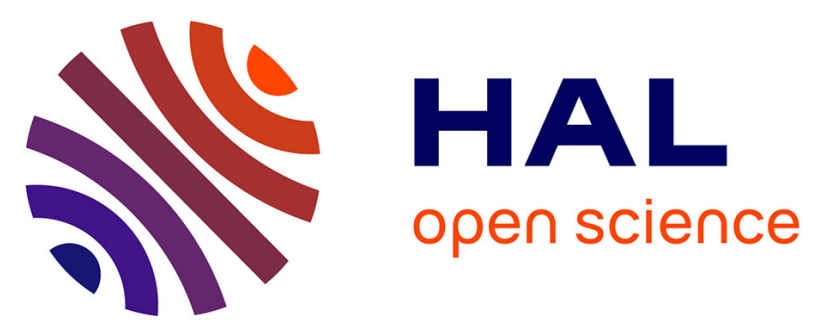

\title{
Simultaneous evaluation of six human glucuronidation activities in liver microsomes using liquid chromatography-tandem mass spectrometry.
}

Anne-Laure Gagez, Koukeb Rouguieg-Malki, François-Ludovic Sauvage, Pierre Marquet, Nicolas Picard

\section{To cite this version:}

Anne-Laure Gagez, Koukeb Rouguieg-Malki, François-Ludovic Sauvage, Pierre Marquet, Nicolas Picard. Simultaneous evaluation of six human glucuronidation activities in liver microsomes using liquid chromatography-tandem mass spectrometry.: Simultaneous evaluation of glucuronidation activities. Analytical Biochemistry, 2012, 427 (1), pp.52-9. 10.1016/j.ab.2012.04.031 . inserm-00697479

\section{HAL Id: inserm-00697479 https://www.hal.inserm.fr/inserm-00697479}

Submitted on 15 May 2012

HAL is a multi-disciplinary open access archive for the deposit and dissemination of scientific research documents, whether they are published or not. The documents may come from teaching and research institutions in France or abroad, or from public or private research centers.
L'archive ouverte pluridisciplinaire HAL, est destinée au dépôt et à la diffusion de documents scientifiques de niveau recherche, publiés ou non, émanant des établissements d'enseignement et de recherche français ou étrangers, des laboratoires publics ou privés. 
Simultaneous evaluation of six human glucuronidation activities in liver microsomes using liquid chromatography-tandem mass spectrometry

Anne-Laure GAGEZ ${ }^{1,2^{*}}$, Koukeb ROUGUIEG-MALKI ${ }^{1,2^{*}}$, François-Ludovic SAUVAGE $^{1,3}$, Pierre MARQUET ${ }^{1,2,3}$, Nicolas PICARD ${ }^{1,2,3}$

${ }^{1}$ Inserm, UMR-S850, Limoges, F-87025, France; ${ }^{2}$ Univ Limoges, Limoges, F-87025, France; ${ }^{3} \mathrm{CHU}$ Limoges, Hôpital Dupuytren, Service de Pharmacologie, Toxicologie et Pharmacovigilance, Limoges, F-87042, France.

*These authors contributed equally to this work.

Running title: Simultaneous evaluation of glucuronidation activities

\section{Address correspondence to:}

Dr. Nicolas PICARD, Inserm UMR-S850, Faculté de Médecine, 2 rue du Dr Marcland, 87025 Limoges cedex, France

Tél: +33555435895 ; Fax: +33555435936 ; E-mail: nicolas.picard@unilim.fr

Subject category: enzymatic assays and analyses 


\begin{abstract}
This article describes the development of a procedure for the simultaneous evaluation of the activity of six different UDP-glucuronyltransferases (UGT) in human liver microsomes (HLM). The method consists of incubations of probe substrates for UGT1A1 (etoposide), UGT1A3 (chenodeoxycholic acid), UGT1A4 (trifluoperazine), UGT1A6 (serotonin), UGT1A9 (mefenamic acid) and UGT2B7 (azidothymidine) with HLM. The six substrates were divided into three different incubations (etoposide + mefenamic acid; chenodeoxycholic acid + serotonin + azydothymidine, and trifluoperazine alone), the media of which were pooled before analysis. Glucuronide formation rates were determined in a single-run of 20 minutes using a validated liquid chromatography-tandem mass spectrometry method. No significant difference was observed between glucuronidation activities measured using the present procedure and individual incubations of the probes. The method was used successfully for the determination of UGT activities in 44 individual HLM preparations and for the phenotyping of preparations predicted to have altered UGT1A1 and UGT2B7 activities because of known genetic polymorphisms.
\end{abstract}

Keywords: UDP-glucuronosyltransferase; microsomes; liquid chromatography; tandem mass spectrometry; drug metabolism 


\section{Introductory statement}

Glucuronidation is a major drug metabolic pathway, catalyzed by uridine diphosphate (UDP)-glucuronosyltranferases (UGT). Two main families of UGTs have been identified in humans, namely UGT1A and UGT2 (subdivided in UGT2A and UGT2B) [1, 2]. The UGT 1A family consists of 9 functionally active proteins: UGT 1A1, 1A3, 1A4, 1A6 and 1A9, predominantly expressed in the liver, and UGT1A5, 1A7, 1A8 and 1A10 which are almost exclusively extrahepatic [3,4]. The UGT2A (2A1, 2A2 and 2A3) enzymes are found mainly in olfactory tissues, although UGT2A3 might also be expressed in significant amount in the liver [5, 6]. The UGT2B subfamily comprises seven functional members (UGT2B4, 2B7, 2B10, 2B11, 2B15, 2B17, and 2B28) [3], with several expressed in the liver (UGT2B4, 2B7, 2B10, 2B15, and 2B17).

Drug glucuronides are hydrophilic products which are excreted in the urine or bile [7]. They usually exhibit lower pharmacological activity, but in a number of cases they can be more active than the parent compound (e.g., morphine-6-glucuronide) [8] or highly reactive (e.g., acyl-glucuronides) [9]. In addition, drug glucuronidation exhibits substantial interindividual variability which can result in altered drug pharmacological profiles [10]. It thus becomes increasingly apparent that the study of drug glucuronidation has to be included in the process of enzyme reaction phenotyping during drug development, but this requires qualified biological systems (e.g., liver microsomes, hepatocytes) with known enzyme contents or activities. In this context, several authors have proposed UGT phenotyping assays. However, the assays are based on various analytical techniques and are usually dedicated to one particular isoform [5, 11-14]. Only Donato et al. reported a single liquid chromatography-tandem mass spectrometry (LC- 
MS/MS) method which can be applied to the activity measurements of four major human hepatic UGTs (1A1, 1A6, 1A9 and 2B7) [15].

The present work aimed at establishing a $n$-in one assay to phenotype six major human UGTs (UGT1A1, 1A3, 1A4, 1A6, 1A9 and 2B7) in human liver microsomes (HLM), using incubations of selective substrates followed by a single LC-MS/MS determination of their glucuronides. The procedure allowed the description of hepatic glucuronidation interindividual variability in a bank of 44 HLM.

\section{Materials and Methods}

\section{Chemicals and reagents}

Etoposide (ETO), chenodeoxycholic acid (CDCA), serotonin (SER), mefenamic acid (MEF), trifluoperazine (TFP), alamethicin, UDP-glucuronic acid (UDPGA), estradiol, dimethyl sulfoxide (DMSO) and glafenine (GLF) were obtained from Sigma-Aldrich (St Louis, MO). $\mathrm{MgCl}_{2}$ was purchased from Merck (Darmstadt, Germany) and Tris-HCl from Qbiogene (Solon, OH). Azidothymidine (AZT) was provided by GlaxoSmithKline (Nanterre, France). All reagents were of analytical grade.

\section{Enzymes and microsomes}

A pool of mixed men and women HLM as well as microsomes prepared from baculovirus-infected insect cells expressing the human UGT1A1, 1A3, 1A4, 1A6, 1A9, 2B4, 2B7, 2B15 and 2B17 (Supersomes ${ }^{\circledR}$ ), and a control preparation, were purchased from BD Biosciences Gentest (Woburn, MA).

Human liver tissue samples derived from 44 surgical specimens were obtained from Biopredic International (Rennes, France). All samples were collected after singular 
donors had given their informed consent, in accordance with the French bioethics laws. The genomic DNA of each liver sample had been previously extracted and genotyped for the UGT1A1 TA repeat $(U G T 1 A 1 * 28)$ and $U G T 2 B 7 \quad-842 \mathrm{G}>\mathrm{A} \quad$ (rs7438135) polymorphisms as reported recently [16]. Genotype distributions were in HardyWeinberg equilibrium. Individual human liver microsomes (HLM) were prepared as previously described [17]. Briefly, liver samples were homogenized in a $50 \mathrm{mM} \mathrm{pH} 8$ phosphate buffer containing $0.25 \mathrm{M}$ saccharose, $10 \mathrm{mM}$ EDTA and $0.1 \mathrm{mM}$ dithiothreitol following a two-step disruption process using an Ultraturax homogenizer (IKA Werke, Staufen, Germany) and a Dounce homogenizer (Wheaton, Millvill, USA). The microsomal fraction was then obtained by differential centrifugation as described [17]. Microsomes were suspended in $0.1 \mathrm{mM}$ phosphate buffer $\mathrm{pH} 8.0$ containing $1 \mathrm{mM}$ EDTA, $1 \mathrm{mM}$ dithiothreitol and $20 \%$ glycerol (v:v). The suspension was divided into aliquots and stored at $-80^{\circ} \mathrm{C}$. Protein concentration was measured according to the Bradford's method using bovine serum albumin as standard.

\section{Assay incubation conditions and sample preparation}

All incubations were done under linear conditions with respect to time and protein concentration. The incubation buffer consisted of $0.1 \mathrm{M}$ Tris- $\mathrm{HCl}$ (final $\mathrm{pH}=7.4$ ) containing $10 \mathrm{mM} \mathrm{MgCl}$. Incubations contained either an individual substrate or a mixture of substrates $(20 \mu \mathrm{L})$. Substrate stock solutions were prepared in DMSO at a 120X concentration and stored at $+4^{\circ} \mathrm{C}$. Solutions at a $40 \mathrm{X}$ concentration were obtained by diluting stock solutions with DMSO (individual substrate), or with two or three other individual substrate stock solutions. The $40 \mathrm{X}$ solutions were then diluted to $1 \mathrm{X}$ solutions in the incubation buffer before each experiment. Microsomes were diluted in the 
incubation buffer to a concentration of $2.5 \mathrm{mg} / \mathrm{mL}$ and then activated by incubation with an equal volume of alamethicin $(0.25 \mathrm{mg} / \mathrm{mL}$ in incubation buffer $)$ for $15 \mathrm{~min}$ on ice. Typical incubations $(50 \mu \mathrm{L})$ contained: $20 \mu \mathrm{L}$ of activated microsomes (HLM or Supersomes; $0.5 \mathrm{mg} / \mathrm{mL}$ final concentration), $10 \mu \mathrm{L}$ of the co-substrate (UDPGA prepared in the incubation buffer; $2 \mathrm{mM}$ final concentration), and $20 \mu \mathrm{L}$ of $1 \mathrm{X}$ substrate solutions (final concentrations given in Table 1). DMSO final concentration in incubation medium was $0.5 \%(\mathrm{v}: \mathrm{v})$.

Substrates and microsomes were pre-incubated for $5 \mathrm{~min}$ at $37^{\circ} \mathrm{C}$ in a shaking water bath and the reaction initiated by addition of the co-substrate. After $60 \mathrm{~min}$ at $37^{\circ} \mathrm{C}$, reactions were quenched with $40 \mu \mathrm{L}$ of ice cold methanol. Samples were vortex-mixed and centrifuged at $10,000 \mathrm{~g}$ for $5 \mathrm{~min}$. $45 \mu \mathrm{L}$ of the supernatant (incubation of individual substrates) or a mixture of TFP incubation supernatant $(10 \mu \mathrm{L})$ with the supernatants of incubation $\mathrm{A}(45 \mu \mathrm{L})$ and $\mathrm{B}(45 \mu \mathrm{L})$ were transferred to HPLC vials containing $15 \mu \mathrm{L}$ glafenine (GLF; $5 \mathrm{mg} / \mathrm{L}$ ) as the internal standard.

\section{Substrate specificty test}

The specificity of each substrate for its selected enzyme was evaluated by incubating all recombinant UGT (rUGT) preparations with each individual probes at the following concentrations: ETO $(62.5 \mu \mathrm{M})$, CDCA $(37.5 \mu \mathrm{M})$, TFP $(100 \mu \mathrm{M})$, SER $(100 \mu \mathrm{M})$, MEF $(0.5 \mu \mathrm{M})$ and AZT $(62.5 \mu \mathrm{M})$. Experiments were performed in duplicate.

\section{Enzyme kinetics}

Increasing concentrations of each substrate (10 $\mu \mathrm{M}-750 \mu \mathrm{M}$ for ETO, CDCA, TFP, MEF; $10 \mu \mathrm{M}-2000 \mu \mathrm{M}$ for SER and AZT) were incubated both with pooled HLM and its selective rUGT, following the procedure described above. Kinetics were model-fitted and 
kinetic parameters estimated using GraphPad Prism version 5.01. Best-fit models were selected among the following: Michaelis-Menten, substrate inhibition and substrate autoactivation (Hill) models, on the basis of the Akaike Information Criterion.

\section{Interaction between UGT probes}

Potential interactions between UGT probes were examined by incubating pooled HLM with each substrate alone or in combination with each other substrate following the general incubation procedure described above ( $\mathrm{n}=2$ experiments performed in duplicate).

\section{LC-MS/MS method}

The 6 substrates and their metabolites were determined in the same 20 min run. The chromatographic system consisted of a binary pump (Shimadzu LC-20AD) and an autosampler (Shimadzu SIL-20AC) equipped with a $100 \mu \mathrm{L}$ sample loop. The separation was achieved with a Waters Atlantis T3 column ( 150 x $2.1 \mathrm{~mm}$ I.D., particle size $5 \mu \mathrm{m})$. The mobile phase (flow rate: $200 \mu \mathrm{L} / \mathrm{min})$ consisted of solution A ( $0.1 \%$ formic acid in HPLC-grade water; v:v) and solution B ( $0.1 \%$ formic acid in methanol; v:v) that formed the following gradient: $0-1.5 \min (3 \%$ B v:v); $1.5-2.5 \min (20 \%$ B v:v); $2.5-4.5 \min (40 \%$ B v:v); 4.5-5.5 $\min (70 \% \mathrm{~B}$ v:v); 5.5-10.5 $\min (90 \% \mathrm{~B}$ v:v); $10.5-16 \min (90 \% \mathrm{~B}$ v:v); $16-16.5 \min (3 \% \mathrm{~B} \mathrm{v}: \mathrm{v}) ; 16.5-20 \min (3 \% \mathrm{~B} \mathrm{v}: \mathrm{v})$. The column was maintained at $25^{\circ} \mathrm{C}$ and the autosampler at $+4^{\circ} \mathrm{C}$.

The detection was performed using an Applied Biosystems 4000 QTRAPTM mass spectrometer equipped with a Turbo V Ionspray source and controlled by Analyst ${ }^{\circledR} 1.5$ software. Ionization was in the positive mode and acquisition in the Multiple Reaction Monitoring (MRM) mode using two transitions for each probe and three for each glucuronide. The MRM transitions of the parent probes were selected using infusion of 
pure compounds $(1 \mathrm{mg} / \mathrm{L})$. In the absence of pure compounds, the MRM transitions of the glucuronides were based on fragment ions identified when analyzing the incubation supernatants using the so-called "enhanced product ion scan mode". The retention time and MRM transitions of the different compounds are given in Table 2. An example of a chromatogram is presented in Figure 1.

All glucuronide concentrations were estimated as molar equivalents with respect to the calibration curve of the respective parent probe. Stock solutions of individual substrates $(1 \mathrm{~g} / \mathrm{L})$ were prepared in methanol and stored at $+4^{\circ} \mathrm{C}$. Before each analysis, a solution mix of the 6 substrates at $100 \mathrm{mg} / \mathrm{L}$ was prepared in the incubation buffer (Tris- $\mathrm{HCl} 0.1$ $\mathrm{M} ; \mathrm{pH}=7.4$ containing $10 \mathrm{mM} \mathrm{MgCl}_{2}$ ). Calibrating standards at 5, 10, 25, 50, 100, 250, $500,1000,2500$ and $5000 \mu \mathrm{g} / \mathrm{L}$ were then prepared by cascade dilutions in incubation buffer/methanol (56/44\% v/v) before each run. After vortex-mixing, $45 \mu \mathrm{L}$ of each standard were transferred to HPLC vials containing $15 \mu \mathrm{L}$ of GLF $(5 \mathrm{mg} / \mathrm{L}$ in methanol) as the internal standard.

\section{Analytical validation}

Intra-assay precision was studied by preparing and analyzing 5 independent replicates of quality controls prepared as described above at different concentrations: $40 \mu \mathrm{g} / \mathrm{L}, 80$ $\mu \mathrm{g} / \mathrm{L}, 200 \mu \mathrm{g} / \mathrm{L}, 400 \mu \mathrm{g} / \mathrm{L}, 800 \mu \mathrm{g} / \mathrm{L}, 2,000 \mu \mathrm{g} / \mathrm{L}$ and 4,000 $\mu \mathrm{g} / \mathrm{L}$, on a given day. Interassay precision and linearity were evaluated from the analysis of a calibration set each day for 5 days.

To evaluate the stability of glucuronides after incubation, $n=3$ incubations of each substrate with pooled HLM were performed as described above. One aliquot of incubation supernatants was processed immediately after the reaction had been quenched. 
Two other aliquots of the same supernatants were kept at $+4^{\circ} \mathrm{C}$ for $6 \mathrm{~h}$ and at $-20^{\circ} \mathrm{C}$ for 24 h prior to analysis. A fourth aliquot was used to study the stability of the glucuronides over three freeze $\left(-20^{\circ} \mathrm{C}\right) /$ thaw (room temperature) cycles. Deviations of mean glucuronide concentrations in the samples stored at $+4^{\circ} \mathrm{C},-20^{\circ} \mathrm{C}$ or submitted to freeze/thaw cycles from the concentrations measured immediately after incubation were used as an indicator of glucuronide stabilities.

The stability of the glucuronides in the processed samples (auto-sampler stability) was assessed over $14 \mathrm{~h}$ at $4^{\circ} \mathrm{C}$. Triplicate incubation samples were analyzed at time 0 and were then reinjected after $14 \mathrm{~h}$. The mean concentrations of glucuronides after $14 \mathrm{~h}$ were compared to those measured at $\mathrm{t}=0$.

\section{Statistical analysis.}

Statistical analysis to compare glucuronidation rates obtained using the $n$-in one strategy and individual incubations of each probe, and to evaluate genotype-phenotype relationships were carried out using the nonparametric Mann-Whitney and KruskalWallis tests, respectively. Two-tailed $\mathrm{p}<0.05$ was considered statistically significant. Statistical comparisons were performed using GraphPad (version 5.01, San Diego, CA).

\section{Results}

\section{Substrate selection}

Candidate probe substrates for UGT 1A1, 1A3, 1A4, 1A6, 1A9, and 2B7 were selected based on the literature and their suitability for the LC-MS/MS method (Table 1). Figure 2 illustrates the results of incubating the selected probes with rUGT 1A1, 1A3, 1A4, 1A6, 
1A9, 2B7, 2B15 and 2B17. CDCA and TFP were metabolized exclusively by UGT1A3 and 1A4, respectively. AZT, ETO and MEF were selectively metabolized by their respective enzyme (UGT2B7, 1A1, and 1A9, respectively) with minor involvement $(<10 \%)$ of other UGTs (Figure 2).

The glucuronidation of SER was catalyzed by UGT1A6 and UGT2B17 but the activity of UGT1A6 was over fivefold greater than the activity observed with UGT2B17.

Kinetic experiments with both HLM and rUGT were then performed in order to determine the concentration-range of linear metabolism. ETO and MEF showed typical Michaelis-Menten kinetics whereas the glucuronidation of CDCA and TFP was bestfitted by the substrate inhibition equation (Table 1). AZT and SER glucuronidation velocity rates were linear up to $2000 \mu \mathrm{M}$; higher concentration resulted in low solubility or high DMSO concentration $(>5 \%)$ which precludes kinetic parameter determinations for these two substrates. The concentrations of the probes to be used in the assay were chosen to be the closest to the apparent $K_{m}$ of the enzyme and to allow the detection of the metabolites by LC-MS/MS.

n-in one procedure development

Once the selective substrates and their concentrations were chosen as described above, this study investigated potential interactions between UGT probes. ETO glucuronidation was substantially enhanced by SER (median $+21 \%$; $[\min +17$; $\max +40])$ while it tended to be decreased by CDCA $(-20 \%$; [+2; -34]), AZT $(-18 \%$; $[-12 ;-34])$ and TFP $(-22 \%$; [-2; -27]). On the other hand, ETO inhibited CDCA glucuronidation (-23\%; [-12; -42]). TFP also markedly inhibited the glucuronidation of CDCA (-28\% [-31; -17]) and AZT (-42\%; $[-29 ;-47])$ while its own glucuronidation was substantially decreased by CDCA $(-31 \%$ [- 
$25 ;-41])$. No change greater than $15 \%$ of control metabolic rates was observed for other substrate combinations. We finally retained an $n$-in one procedure involving three separate incubations performed in parallel (A: ETO+MEF; B: CDCA+SER+AZT and TFP alone) which were pooled before LC-MS/MS analysis. In order to minimize the dilution effect for the glucuronides with the highest analytical quantitation limits, the pool consisted of $45 \%$ of the supernatants of incubation A and B and 10\% of TFP incubation supernatant. Five independent experiments consisting of duplicate incubations of the substrates, separately or following the $n$-in one procedure, were performed. In each case, there was a close agreement between individual and pooled incubations with insignificant differences in velocity rates of $4.3 \%$ - 18\%, depending on the substrate (Figure 3).

The relative standard deviation (RSD\%) of the results obtained with the $n$-in one procedure, evaluated by phenotyping the same HLM preparation in five independent experiments, ranged from 4.3 to $26.7 \%$.

\section{Analytical validation}

Calibration curves studied using least-square quadratic regression gave excellent correlation coefficients for all six compounds (Table 3). The method showed good intraassay precisions for all compounds, with mean relative errors (MRE) less than $16.5 \%$ and relative standard deviations (RSD) values always less than $16.0 \%$. Inter-assay precision was also good for all compounds over the concentration range, with MRE less than $18.9 \%$ and RSD less than $8.6 \%$ (Table 3 ).

The glucuronides produced during incubation were found to be stable for at least $6 \mathrm{~h}$ at $+4^{\circ} \mathrm{C}$ and $24 \mathrm{~h}$ at $-20^{\circ} \mathrm{C}$ to tolerate at least 3 freeze-thaw cycles (Table 4). The processed sample stability at $+4^{\circ} \mathrm{C}$ (auto-sampler stability) was demonstrated over $14 \mathrm{~h}$. 
UGT glucuronidation rates in HLM and effect of frequent polymorphisms.

The $n$-in one procedure was used to measure glucuronidation enzyme activities in 44 individual HLM. The sensitivity of the assay was sufficient to accurately determine the different UGT activities in all samples. The distribution of UGT1A1, 1A3, 1A4, 1A6, 1A9 and 2B7 activities are depicted in Figure 4. The UGTs showed different extents of variability in activities. Only a two-fold difference was observed between the lowest and highest UGT1A9 activity. All other UGTs had higher activity ranges, with 8- to 16-fold variation between the minimal and the maximal values.

We investigated the effect of two frequent genetic polymorphisms in UGTIAl and $U G T 2 B 7$ on the glucuronidation activities of these two enzymes. The $U G T 1 A I * 28$ allele was associated with a significant decrease in glucuronidation of ETO $(\mathrm{p}=0.0078)$ and the UGT2B7 -842G>A promoter polymorphism with significantly increased glucuronidation of AZT (p=0.0009) (Figure 5). 


\section{Discussion}

This article describes the development of a $n$-in one assay for assessing the activity of six major human hepatic UGTs in microsomes. The procedure yields similar results to a procedure involving individual incubations of UGT probes and allows accurate measurement of UGT activities in a bank of 44 genotyped HLM.

Selective probes for six major human liver UGTs (UGT1A1, 1A3, 1A4, 1A6, 1A9, and 2B7) were chosen from the literature. Watanabe et al. showed that ETO glucuronidation is a specific marker of UGT1A1 using experiments with a panel of recombinant human enzymes and inhibition studies with typical UGT substrates in HLM [18]. Similarly, UGT1A3 was reported to be specifically responsible for the formation of the major metabolite of CDCA (namely CDCA-24-acyl-glucuronide) based on experiments with rUGT and correlation analyses between the glucuronidation of CDCA and that of two other typical UGT1A3 substrates in HLM [19]. TFP was characterized as a specific probe substrate for UGT1A4 using experiments with individual UGTs stably expressed in human embryonic kidney (HEK) 293 cells, chemical inhibition experiments with HLM and comparative kinetics analysis [5]. Similarly, experiments with HEK293 cells stably expressing UGTs showed that AZT is specifically metabolized into 3'-azido-3'-deoxy-5'glucuronylthymidine by UGT2B7 [20]. Accordingly, UGT1A1, 1A3, 1A4 and 2B7 were the only UGTs of the nine tested here able to conjugate ETO, CDCA, TFP and AZT, respectively, confirming that these substrates are excellent markers for these UGTs.

We could also confirm the knowledge that SER is a highly selective probe substrate for UGT1A6 [21] but the contribution of UGT2B17, although minor, should not be excluded. In the case of UGT1A9, we selected MEF instead of propofol (a more commonly used 
probe for UGT1A9) [15]. Propofol indeed showed unsuitable ionization and chromatographic characteristics for the present LC-MS/MS method. MEF has been successfully used as a competitive inhibitor of UGT1A9 in different studies [22, 23] and the present study demonstrated that it is a selective substrate for UGT1A9, with minor contributions of UGT1A1 and UGT1A4. A limitation of this study is that we did not include in this assay selective substrates for UGT2B17 (expressed in the human prostate but also in the liver), UGT2B4 and more regrettably for UGT2B15. No selective substrate has been identified so far for UGT2B17 and apart from its major role in androgen metabolism [24], its contribution to drug metabolism remains to be ascertained. Similarly, UGT2B4, reported as the most abundant UGT in the liver, appears to exhibit low activity towards drugs, and has no selective substrate identified [25]. Its high hepatic expression may be due to its crucial role in the glucuronidation of potentially hepatotoxic bile acids [10]. In contrast to the two above-mentioned UGTs, UGT2B15 is thought to be an important contributor to drug metabolism [25]. Further work needs to be done to establish whether S-oxazepam (a probe recently described for this enzyme), can be included in the present procedure [26]. It has to be noted that none of the probes selected for UGT1A and UGT2B7 were found to be metabolized by UGT2B15. As mentioned earlier, UGT2B17 was found to metabolize SER but its activity was approx. 5-time less than that observed for the selective enzyme UGT1A6. On the other hand, UGT2B4 was found to metabolize MEF with an activity representing 9.4\% of the activity of UGT1A9. Its activity toward AZT, previously reported by others [27], was not detected here, which is presumably explained by the fact that 10 -times lower concentrations were used here. 
Kinetics experiments were performed in order to select the concentrations to be used in the assay. In accordance with previous reports, ETO glucuronidation followed the classical Michaelis-Menten model [18] and TFP glucuronidation the substrate inhibition model [5]. The $K_{m}$ estimated for these pathways were comparable to those previously reported using HLM (ETO: $K_{m}=414 v s 440 \mu \mathrm{M}$ and TFP: $K_{m}=23 v s 61 \mu \mathrm{M}$ ) or recombinant enzymes (ETO: $K_{m}=568 v s 503 \mu \mathrm{M}$ and TFP $K_{m}=106 v s 39 \mu \mathrm{M}$ ). UGT1A3-mediated glucuronidation of CDCA was best-fitted by the substrate inhibition model whereas Trottier et al. reported Michaelis-Menten kinetics for this pathway [19]. The range of CDCA concentration tested here was higher than that used in this previous publication (10-750 $\mu \mathrm{M}$ vs $1-250 \mu \mathrm{M})$, which probably explain that the authors did not observed substrate inhibition. To accommodate for this difference, we finally selected a $15-\mu \mathrm{M}$ concentration for the assay, a concentration much lower than the $K_{m}$ we observed using HLM $(372 \mu \mathrm{M})$ or rUGT $(130 \mu \mathrm{M})$ and in the range of those reported by Trottier et al. (i.e., $11 \mu \mathrm{M}$ using HLM and $19 \mu \mathrm{M}$ using UGT1A3-HEK293 cell lines) [19]. The glucuronidation of SER and AZT exhibited unsaturable kinetics over the range of substrate concentrations $(10-2000 \mu \mathrm{M})$ which is consistent with the low affinity previously reported for these two substrates $\left(K_{m}=8800\right.$ and $923 \mu \mathrm{M}$, respectively) [21, 28]. The glucuronidation of MEF was best described using the Michalelis-Menten model which is only partly in accordance with the literature: Gaganis et al. reported MichaelisMenten kinetics using human kidney microsomes and Hill kinetics using rUGT1A9. Also the $K_{m}$ estimated here (164 $\mu \mathrm{M}$ using HLM and $11 \mu \mathrm{M}$ using rUGT1A9) were slightly different from those reported by Gaganis et al. ( $23 \mu \mathrm{M}$ using human kidney microsomes and $449 \mu \mathrm{M}$ using recombinant UGT1A9). Owing to the high analytical sensitivity for 
the MEF-glucuronide, we finally retained a concentration of $0.5 \mu \mathrm{M}$, much lower than the apparent $K_{m}$ of HLM.

For each substrate, the concentration selected was lower or close to the apparent $K_{m}$ of the enzymes (i.e., in a linear range with respect to glucuronide formation rates) and allowed accurate determination of metabolite formation rates. Similar conditions were selected in the vast majority of P450 or UGT phenotyping assays [29-31], not only to ensure enzyme specificities but also to allow for the determination of UGT inhibition profiles. Alternatively, the incubation of probes at saturating concentrations has been proposed in order to evaluate the total enzyme functional capabilities [31]. Here, we did not evaluate functional capabilities of UGT at saturating concentrations.

Despite the probes being selectively metabolized by their respective enzymes, significant interactions were observed when co-incubations were performed. We first observed that ETO glucuronidation was increased in presence of SER (approx. + 20\%). It has been previously shown that UGT1A1-catalyzed estradiol glucuronidation can be stimulated by additional UGT1A1 substrates and other compounds [32, 33] through heterotropic activation of the enzyme. The same phenomenon presumably occurred here with SER. We thus decided to split the two substrates into different incubations. In addition, ETO glucuronidation was significantly inhibited by CDCA, TFP and AZT, although none of these substrates was metabolized by UGT1A1. A possible explanation for this could be that non-competitive inhibition occurred, which has been previously described for this enzyme [34]. The mechanism of such inhibition is not fully understood. It is thought to involve the binding of the inhibitor at a site away from the substrate binding site. The existence of distinct substrate and inhibitor binding sites was also suggested for UGT1A4 
[35] and UGT2B7 [36] which might explain the inhibition of these UGTs by CDCA and TFP, respectively. In this study we did not investigate in much detail the mechanism involved in these different interactions because it was far beyond the scope of this study. We decided to develop a $n$-in one strategy. Based on the interactions observed, the six substrates were divided into three different incubations $(\mathrm{ETO}+\mathrm{MEF}$; CDCA + SER + AZT, and TFP alone), the media of which were pooled before analysis. The mean difference between the results obtained with the $n$-in one strategy and individual incubations of the different substrates $(\mathrm{n}=5 \times 2$ experiments) was limited $(<18 \%)$ and was likely due to the experimental variability.

The LC-MS/MS method passed the recommended validation criteria for such analytical methods [37]. Two transitions per substrate and three per glucuronide were selected to ensure specificity, even for compounds not available as commercial pure products. A limitation of our method is that the glucuronides were determined relatively to the calibration curves of their respective parent probe. However, this has no consequence on the relative comparison of enzyme activities (i.e., comparison of enzyme relative activities with and without competitive inhibitor or for a given genotype).

In order to test the applicability of the method, we assayed 44 individual HLM preparations. Glucuronidation activities could be determined in each case, which demonstrates that the method is suitable for the determination of UGT activities in the range expected with this experimental model. In particular, we were able to accurately identify the preparations predicted to have a low or a high activity because of known genetic polymorphisms. We observed a gradual decrease of ETO microsomal metabolism with the increasing number of $U G T 1 A 1 * 28$ allele which is known to decrease UGT1A1 
expression level and activity [38]. On the other hand, the metabolism of AZT was significantly increased by $U G T 2 B 7-842 \mathrm{G}>\mathrm{A}$ SNP which was reported to result in a twofold increase of UGT2B7 transcription [39] and to affect the in vitro metabolism of at least two other UGT2B7 substrates $[16,40]$.

In conclusion, the present assay can be used effectively to rapidly assess glucuronidation activities of 6 major UGTs in HLM. It offers the potential of being automated on 96-well plates to further increase the analytical throughput. This procedure may also be useful for the evaluation of UGT activities using other models (hepatocytes, liver slices) as well as for the screening of potential UGT inhibitors.

\section{Acknowledgments}

We gratefully thank Biopredic International (Rennes, France) for providing us human liver tissue samples and Jean-Hervé Comte for excellent technical support. 


\section{References}

[1]. C. Guillemette, E. Levesque, M. Harvey, J. Bellemare, and V. Menard, UGT genomic diversity: beyond gene duplication, Drug Metab Rev 42 (2010) 24-44.

[2]. P. Lazarus, A. S. Blevins-Primeau, Y. Zheng, and D. Sun, Potential role of UGT pharmacogenetics in cancer treatment and prevention: focus on tamoxifen, Ann $\mathrm{N}$ Y Acad Sci 1155 (2009) 99-111.

[3]. T. Izukawa, M. Nakajima, R. Fujiwara, H. Yamanaka, T. Fukami, M. Takamiya, Y. Aoki, S. Ikushiro, T. Sakaki, and T. Yokoi, Quantitative analysis of UDPglucuronosyltransferase (UGT) 1A and UGT2B expression levels in human livers, Drug Metab Dispos 37 (2009) 1759-68.

[4]. C. P. Strassburg, A. Strassburg, N. Nguyen, Q. Li, M. P. Manns, and R. H. Tukey, Regulation and function of family 1 and family 2 UDP-glucuronosyltransferase genes (UGT1A, UGT2B) in human oesophagus, Biochem J 338 ( Pt 2) (1999) 489-98.

[5]. V. Uchaipichat, P. I. Mackenzie, D. J. Elliot, and J. O. Miners, Selectivity of substrate (trifluoperazine) and inhibitor (amitriptyline, androsterone, canrenoic acid, hecogenin, phenylbutazone, quinidine, quinine, and sulfinpyrazone) "probes" for human udp-glucuronosyltransferases, Drug Metab Dispos 34 (2006) $449-56$.

[6]. M. H. Court, S. Hazarika, S. Krishnaswamy, M. Finel, and J. A. Williams, Novel polymorphic human UDP-glucuronosyltransferase 2A3: cloning, functional characterization of enzyme variants, comparative tissue expression, and gene induction, Mol Pharmacol 74 (2008) 744-54. 
[7]. R. H. Tukey, and C. P. Strassburg, Human UDP-glucuronosyltransferases: metabolism, expression, and disease, Annu Rev Pharmacol Toxicol 40 (2000) $581-616$.

[8]. B. Frances, R. Gout, B. Monsarrat, J. Cros, and J. M. Zajac, Further evidence that morphine- 6 beta-glucuronide is a more potent opioid agonist than morphine, $\mathrm{J}$ Pharmacol Exp Ther 262 (1992) 25-31.

[9]. G. S. Walker, J. Atherton, J. Bauman, C. Kohl, W. Lam, M. Reily, Z. Lou, and A. Mutlib, Determination of degradation pathways and kinetics of acyl glucuronides by NMR spectroscopy, Chem Res Toxicol 20 (2007) 876-86.

[10]. M. H. Court, Interindividual variability in hepatic drug glucuronidation: studies into the role of age, sex, enzyme inducers, and genetic polymorphism using the human liver bank as a model system, Drug Metab Rev 42 (2010) 209-24.

[11]. M. H. Court, Isoform-selective probe substrates for in vitro studies of human UDP-glucuronosyltransferases, Methods Enzymol 400 (2005) 104-16.

[12]. R. Fujiwara, M. Nakajima, H. Yamanaka, M. Katoh, and T. Yokoi, Interactions between human UGT1A1, UGT1A4, and UGT1A6 affect their enzymatic activities, Drug Metab Dispos 35 (2007) 1781-7.

[13]. H. X. Liu, Y. Q. He, Y. Hu, Y. Liu, J. W. Zhang, W. Li, Z. T. Wang, and L. Yang, Determination of UDP-glucuronosyltransferase UGT2B7 activity in human liver microsomes by ultra-performance liquid chromatography with MS detection, J Chromatogr B Analyt Technol Biomed Life Sci 870 (2008) 84-90.

[14]. V. Uchaipichat, P. I. Mackenzie, X. H. Guo, D. Gardner-Stephen, A. Galetin, J. B. Houston, and J. O. Miners, Human udp-glucuronosyltransferases: isoform 
selectivity and kinetics of 4-methylumbelliferone and 1-naphthol glucuronidation, effects of organic solvents, and inhibition by diclofenac and probenecid, Drug Metab Dispos 32 (2004) 413-23.

[15]. M. T. Donato, S. Montero, J. V. Castell, M. J. Gomez-Lechon, and A. Lahoz, Validated assay for studying activity profiles of human liver UGTs after drug exposure: inhibition and induction studies, Anal Bioanal Chem 396 (2010) 2251-

63.

[16]. K. Rouguieg, N. Picard, F. L. Sauvage, J. M. Gaulier, and P. Marquet, Contribution of the different UDP-glucuronosyltransferase (UGT) isoforms to buprenorphine and norbuprenorphine metabolism and relationship with the main UGT polymorphisms in a bank of human liver microsomes, Drug Metab Dispos 38 (2010) 40-5.

[17]. N. Picard, T. Cresteil, A. Premaud, and P. Marquet, Characterization of a phase 1 metabolite of mycophenolic acid produced by CYP3A4/5, Ther Drug Monit 26 (2004) 600-8.

[18]. Y. Watanabe, M. Nakajima, N. Ohashi, T. Kume, and T. Yokoi, Glucuronidation of etoposide in human liver microsomes is specifically catalyzed by UDPglucuronosyltransferase 1A1, Drug Metab Dispos 31 (2003) 589-95.

[19]. J. Trottier, M. Verreault, S. Grepper, D. Monte, J. Belanger, J. Kaeding, P. Caron, T. T. Inaba, and O. Barbier, Human UDP-glucuronosyltransferase (UGT)1A3 enzyme conjugates chenodeoxycholic acid in the liver, Hepatology 44 (2006) $1158-70$. 
[20]. O. Barbier, D. Turgeon, C. Girard, M. D. Green, T. R. Tephly, D. W. Hum, and A. Belanger, 3'-azido-3'-deoxythimidine (AZT) is glucuronidated by human UDPglucuronosyltransferase 2B7 (UGT2B7), Drug Metab Dispos 28 (2000) 497-502.

[21]. S. Krishnaswamy, S. X. Duan, L. L. Von Moltke, D. J. Greenblatt, and M. H. Court, Validation of serotonin (5-hydroxtryptamine) as an in vitro substrate probe for human UDP-glucuronosyltransferase (UGT) 1A6, Drug Metab Dispos 31 (2003) 133-9.

[22]. N. Picard, D. Ratanasavanh, A. Premaud, Y. Le Meur, and P. Marquet, Identification of the UDP-glucuronosyltransferase isoforms involved in mycophenolic acid phase II metabolism, Drug Metab Dispos 33 (2005) 139-46.

[23]. M. A. Wynalda, K. M. Wynalda, B. M. Amore, P. E. Fagerness, and L. C. Wienkers, Characterization of bropirimine O-glucuronidation in human liver microsomes, Xenobiotica 33 (2003) 999-1011.

[24]. M. Beaulieu, E. Levesque, D. W. Hum, and A. Belanger, Isolation and characterization of a novel cDNA encoding a human UDPglucuronosyltransferase active on C19 steroids, J Biol Chem 271 (1996) 2285562.

[25]. J. O. Miners, K. M. Knights, J. B. Houston, and P. I. Mackenzie, In vitro-in vivo correlation for drugs and other compounds eliminated by glucuronidation in humans: pitfalls and promises, Biochem Pharmacol 71 (2006) 1531-9.

[26]. X. He, L. M. Hesse, S. Hazarika, G. Masse, J. S. Harmatz, D. J. Greenblatt, and M. H. Court, Evidence for oxazepam as an in vivo probe of UGT2B15: oxazepam 
clearance is reduced by UGT2B15 D85Y polymorphism but unaffected by UGT2B17 deletion, Br J Clin Pharmacol 68 (2009) 721-30.

[27]. M. H. Court, S. Krishnaswamy, Q. Hao, S. X. Duan, C. J. Patten, L. L. Von Moltke, and D. J. Greenblatt, Evaluation of 3'-azido-3'-deoxythymidine, morphine, and codeine as probe substrates for UDP-glucuronosyltransferase 2B7 (UGT2B7) in human liver microsomes: specificity and influence of the UGT2B7*2 polymorphism, Drug Metab Dispos 31 (2003) 1125-33.

[28]. V. Uchaipichat, L. K. Winner, P. I. Mackenzie, D. J. Elliot, J. A. Williams, and J. O. Miners, Quantitative prediction of in vivo inhibitory interactions involving glucuronidated drugs from in vitro data: the effect of fluconazole on zidovudine glucuronidation, Br J Clin Pharmacol 61 (2006) 427-39.

[29]. E. A. Dierks, K. R. Stams, H. K. Lim, G. Cornelius, H. Zhang, and S. E. Ball, A method for the simultaneous evaluation of the activities of seven major human drug-metabolizing cytochrome P450s using an in vitro cocktail of probe substrates and fast gradient liquid chromatography tandem mass spectrometry, Drug Metab Dispos 29 (2001) 23-9.

[30]. V. Dixit, N. Hariparsad, P. Desai, and J. D. Unadkat, In vitro LC-MS cocktail assays to simultaneously determine human cytochrome P450 activities, Biopharm Drug Dispos 28 (2007) 257-62.

[31]. M. T. Donato, N. Jimenez, J. V. Castell, and M. J. Gomez-Lechon, Fluorescencebased assays for screening nine cytochrome P450 (P450) activities in intact cells expressing individual human P450 enzymes, Drug Metab Dispos 32 (2004) 699706. 
[32]. J. A. Williams, B. J. Ring, V. E. Cantrell, K. Campanale, D. R. Jones, S. D. Hall, and S. A. Wrighton, Differential modulation of UDP-glucuronosyltransferase 1A1 (UGT1A1)-catalyzed estradiol-3-glucuronidation by the addition of UGT1A1 substrates and other compounds to human liver microsomes, Drug Metab Dispos 30 (2002) 1266-73.

[33]. E. Pfeiffer, C. R. Treiling, S. I. Hoehle, and M. Metzler, Isoflavones modulate the glucuronidation of estradiol in human liver microsomes, Carcinogenesis $\mathbf{2 6}$ (2005) 2172-8.

[34]. Y. Liu, J. Ramirez, L. House, and M. J. Ratain, The UGT1A1*28 polymorphism correlates with erlotinib's effect on SN-38 glucuronidation, Eur J Cancer 46 (2010) 2097-103.

[35]. J. Zhou, T. S. Tracy, and R. P. Remmel, Glucuronidation of dihydrotestosterone and trans-androsterone by recombinant UDP-glucuronosyltransferase (UGT) 1A4: evidence for multiple UGT1A4 aglycone binding sites, Drug Metab Dispos 38 $(2010$

) $431-40$.

[36]. V. Uchaipichat, A. Galetin, J. B. Houston, P. I. Mackenzie, J. A. Williams, and J. O. Miners, Kinetic modeling of the interactions between 4-methylumbelliferone, 1-naphthol, and zidovudine glucuronidation by udp-glucuronosyltransferase 2B7 (UGT2B7) provides evidence for multiple substrate binding and effector sites, Mol Pharmacol 74 (2008) 1152-62. 
[37]. F. L. Sauvage, J. M. Gaulier, G. Lachatre, and P. Marquet, Pitfalls and prevention strategies for liquid chromatography-tandem mass spectrometry in the selected reaction-monitoring mode for drug analysis, Clin Chem 54 (2008) 1519-27.

[38]. V. C. Peterkin, J. N. Bauman, T. C. Goosen, L. Menning, M. Z. Man, J. D. Paulauskis, J. A. Williams, and S. P. Myrand, Limited influence of UGT1A1*28 and no effect of UGT2B7*2 polymorphisms on UGT1A1 or UGT2B7 activities and protein expression in human liver microsomes, Br J Clin Pharmacol 64 (2007) 458-68.

[39]. Y. Duguay, C. Baar, F. Skorpen, and C. Guillemette, A novel functional polymorphism in the uridine diphosphate-glucuronosyltransferase $2 \mathrm{~B} 7$ promoter with significant impact on promoter activity, Clin Pharmacol Ther 75 (2004) 22333.

[40]. N. Djebli, N. Picard, J. P. Rerolle, Y. Le Meur, and P. Marquet, Influence of the UGT2B7 promoter region and exon 2 polymorphisms and comedications on Acyl-MPAG production in vitro and in adult renal transplant patients, Pharmacogenet Genomics 17 (2007) 321-30.

[41]. P. Gaganis, J. O. Miners, and K. M. Knights, Glucuronidation of fenamates: kinetic studies using human kidney cortical microsomes and recombinant UDPglucuronosyltransferase (UGT) 1A9 and 2B7, Biochem Pharmacol 73 (2007) 1683-91. 

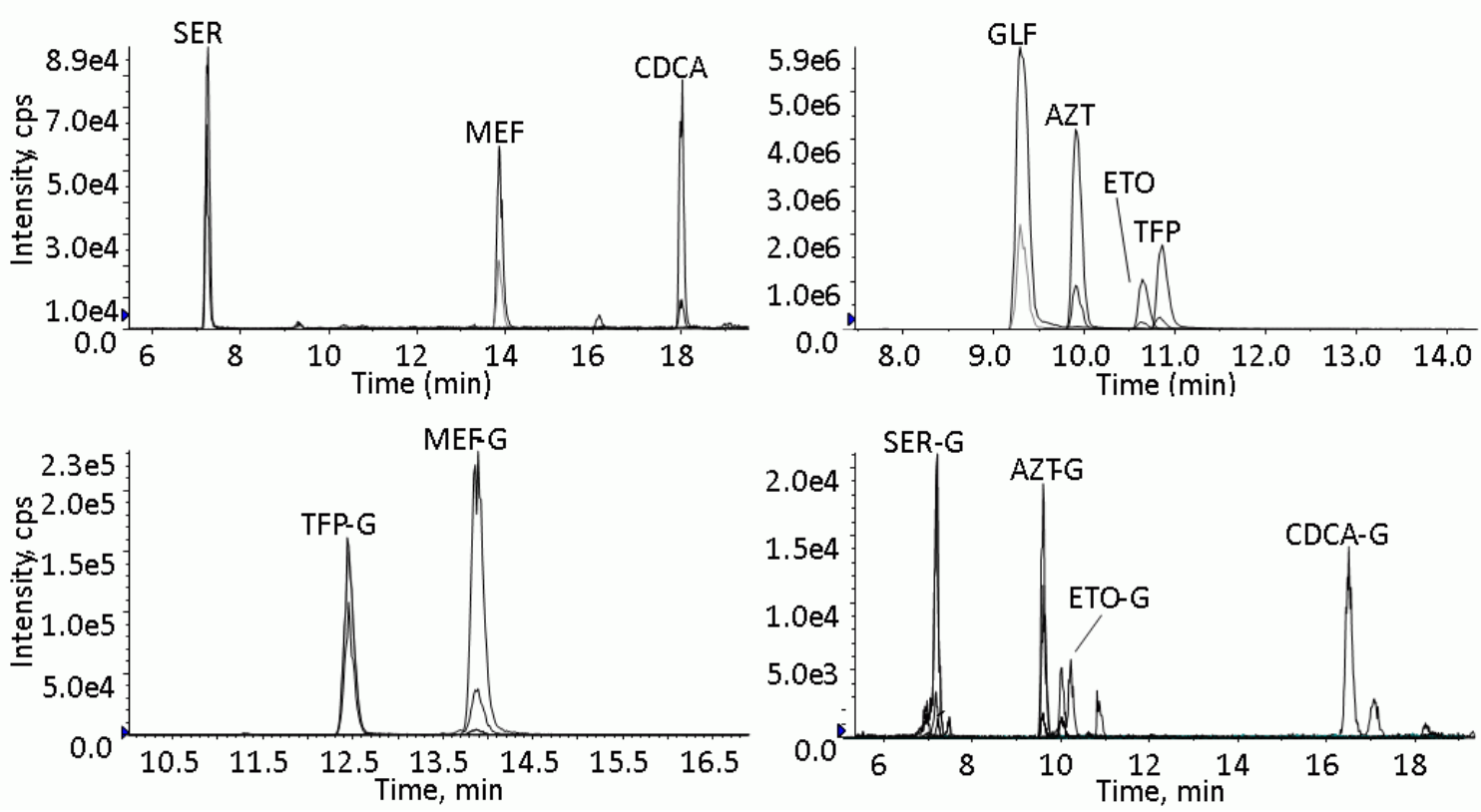

Figure 1. LC-MS/MS chromatogram of etoposide (ETO), chenodesoxycholic acid (CDCA), trifluoroperazine (TFP), serotonine (SER), mefenamic acid (MEF) and azydothymidine (AZT) and their glucuronides after incubation with HLM as described in the materials and methods section. 

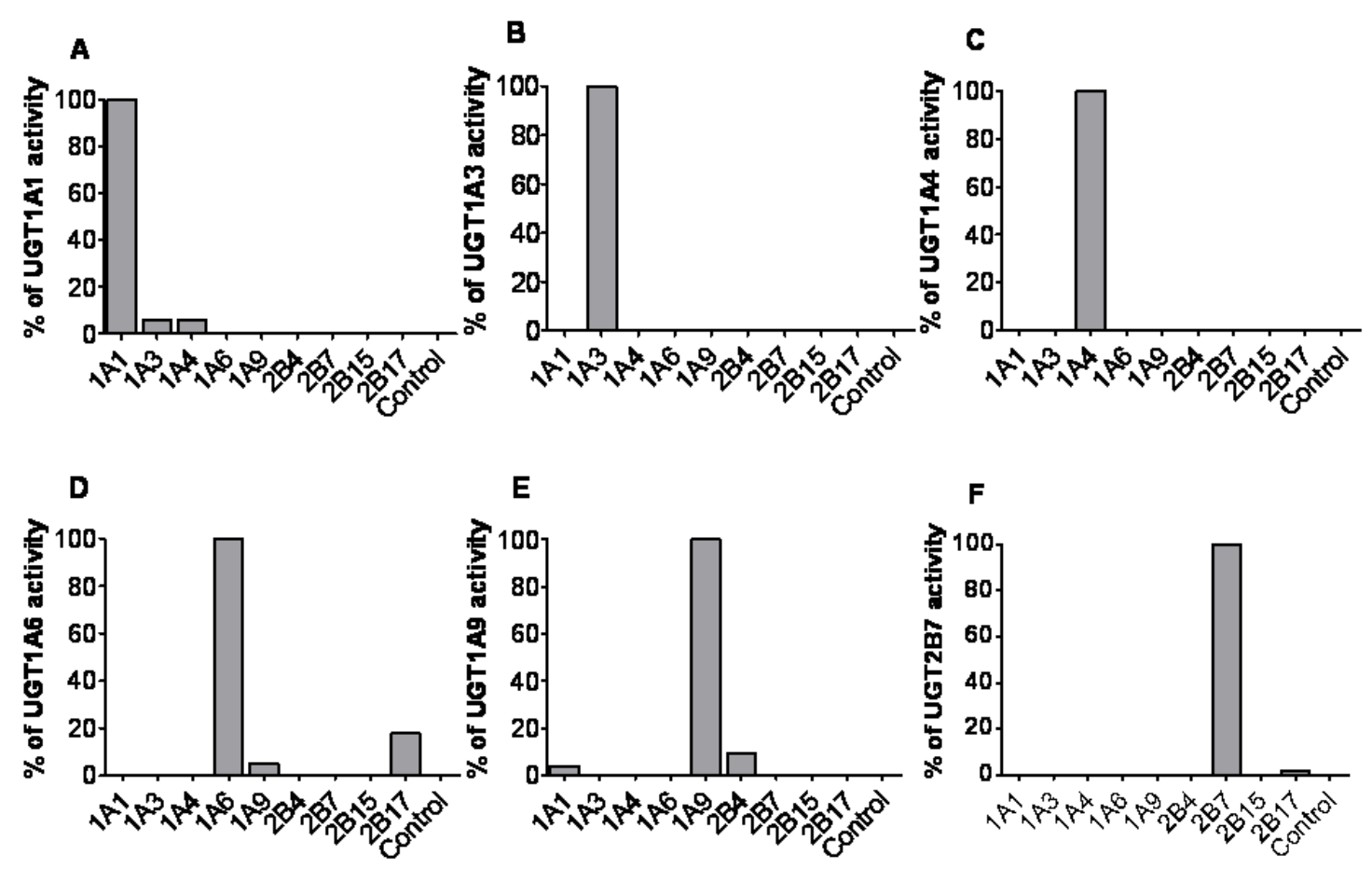

Figure 2. Specificity of etoposide (62.5 $\mu \mathrm{M})(\mathrm{A})$, chenodesoxycholic acid $(37.5 \mu \mathrm{M})(\mathrm{B})$, trifluoroperazine $(100 \mu \mathrm{M})(\mathrm{C})$, serotonine $(100 \mu \mathrm{M})(\mathrm{D})$, mefenamic acid $(0.5 \mu \mathrm{M})(\mathrm{E})$ and azydothymidine $(62.5 \mu \mathrm{M})$ (F) for recombinant UDP-glucuronosyl-transferases. Activity is expressed as a percentage of the activity obtained for the selective form. 


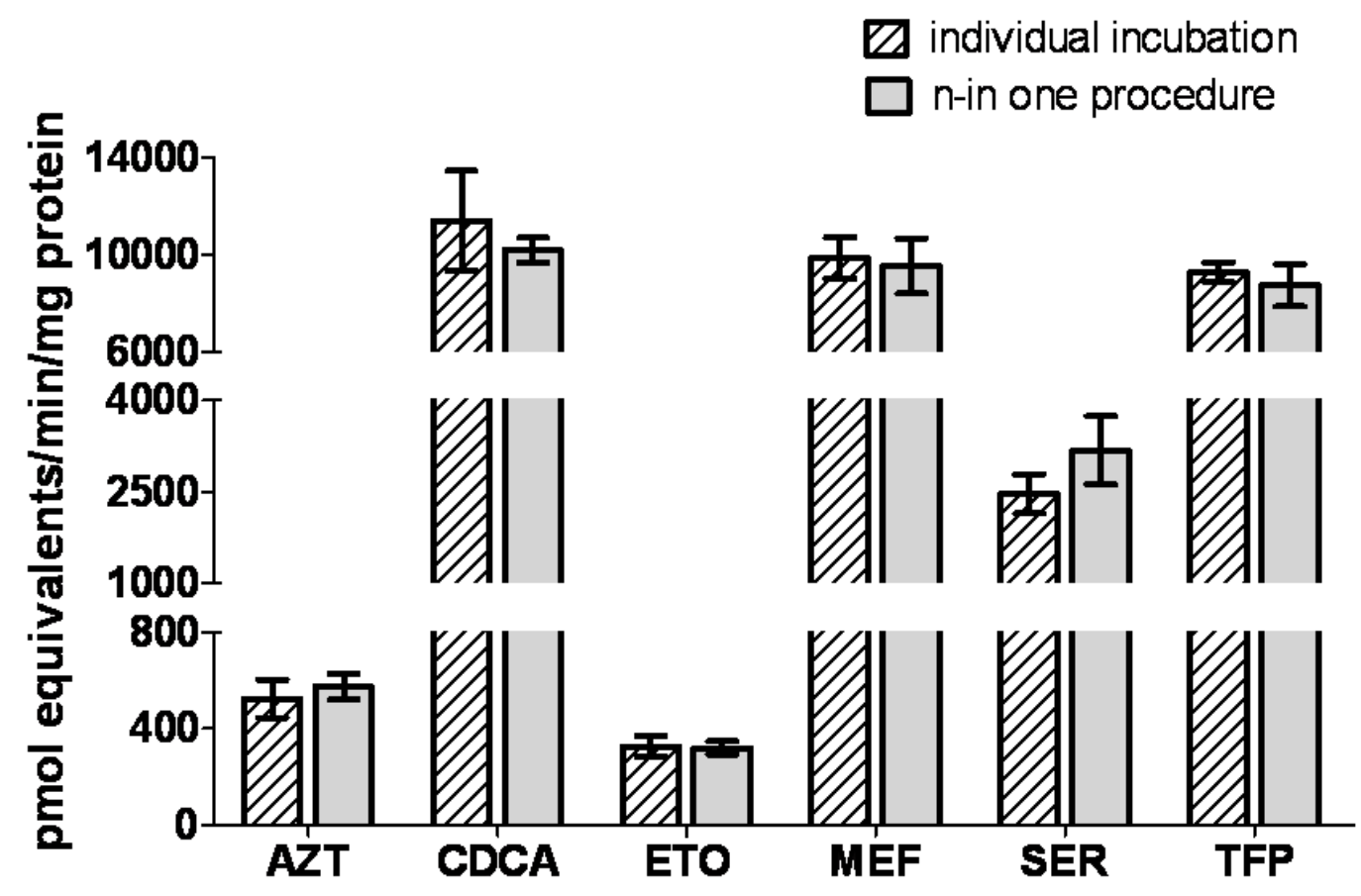

Figure 3. Glucuronidation enzyme activities of pool human liver microsomes obtained following incubations of UGT probes alone or using the n-in one procedure. Activities are means of duplicate incubations performed in 5 independent experiments. 

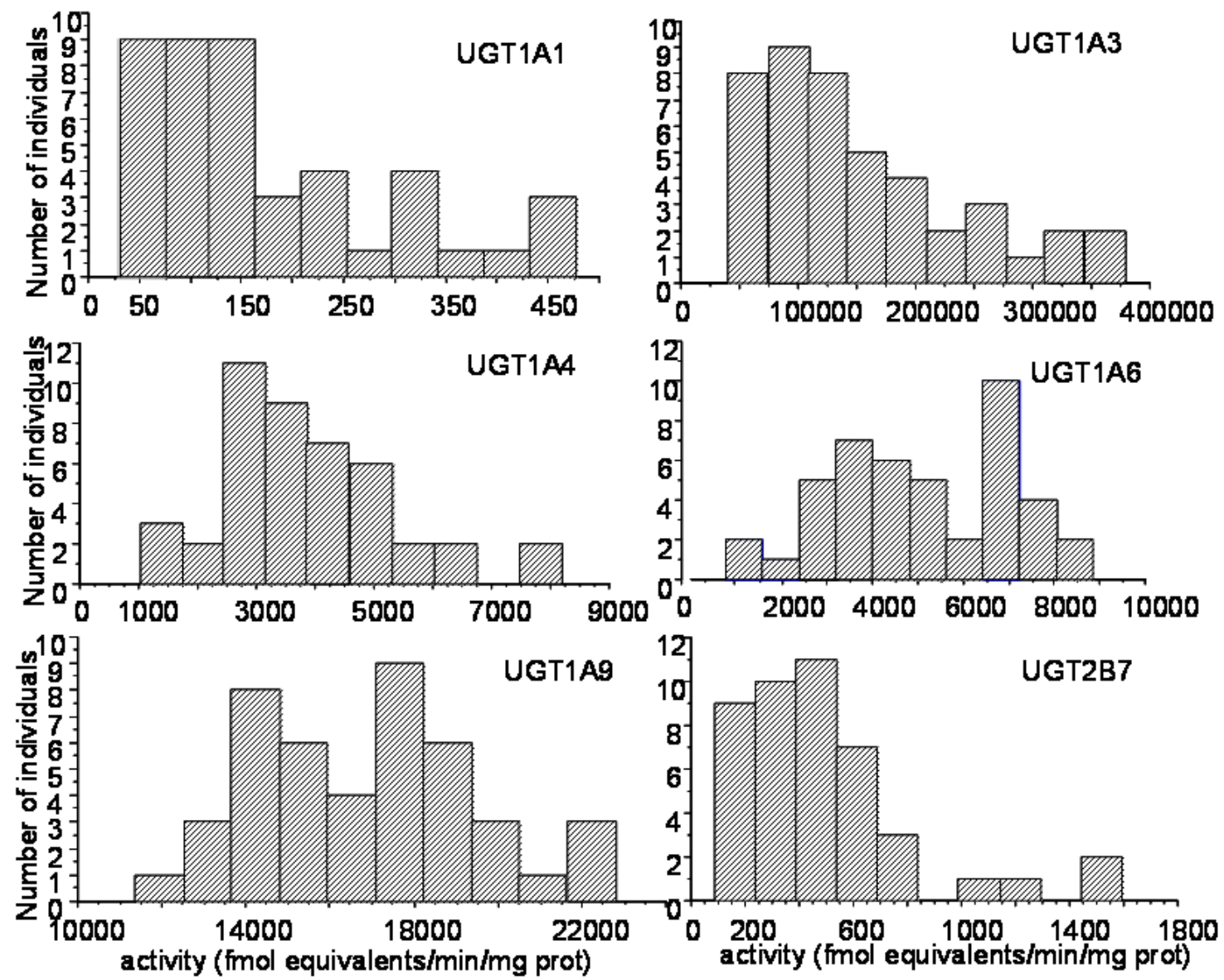

Figure 4. Frequency distribution of UDP-glucuronosyltransferase activities measured using the $\mathrm{n}$-in one procedure in 44 individual human liver microsomes.

Activity is expressed in pmole equivalents $/ \mathrm{min} / \mathrm{mg}$ protein. 

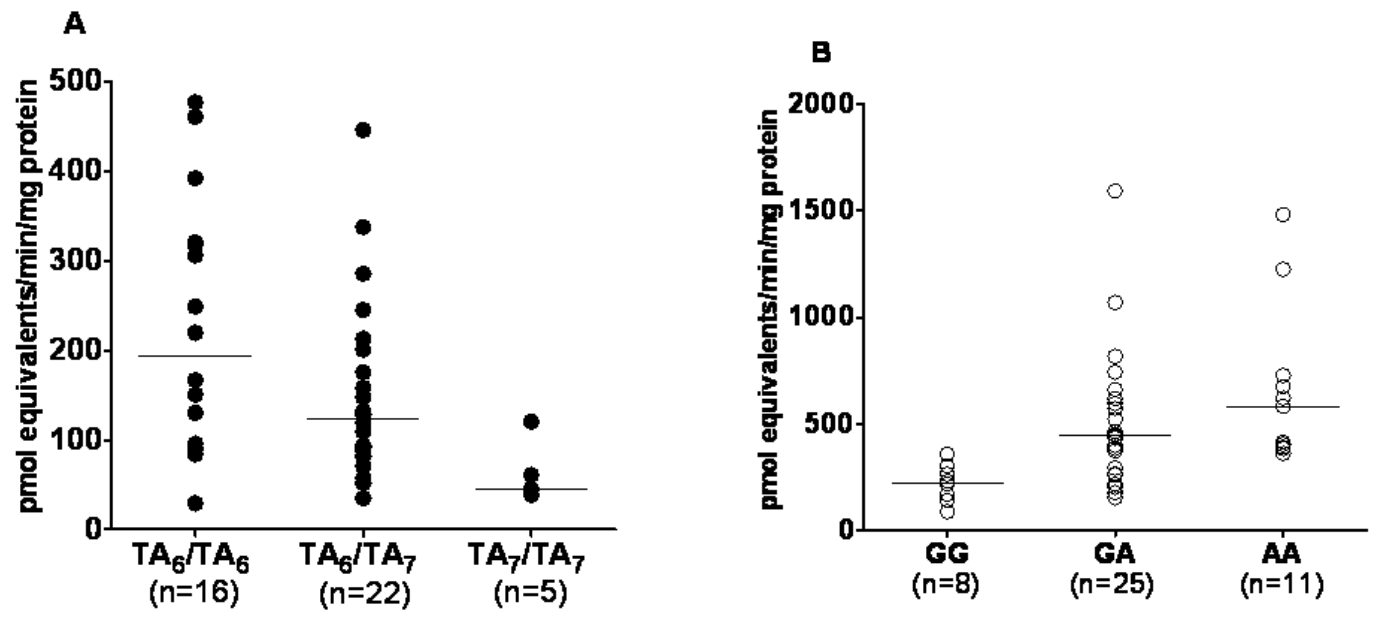

Figure 5. Influence of UGT1A1 TA6/TA7 and UGT2B7 -842G>A polymorphisms on etoposide (A) and azydothymidine (B) activities measured using the $\mathrm{n}$-in one procedure in 44 individual human liver microsomes (the lines represent the median values). $\mathrm{p}=0.0078(\mathrm{~A}) ; \mathrm{p}=0.0009(\mathrm{~B}) .($ One sample remained undetermined for UGT1AI genotype). 
Table 1. UGT probe substrates, concentrations used in the assay and kinetics parameters by human liver microsomes (HLM) and recombinant UDP-glucuronosyltransferases (rUGT).

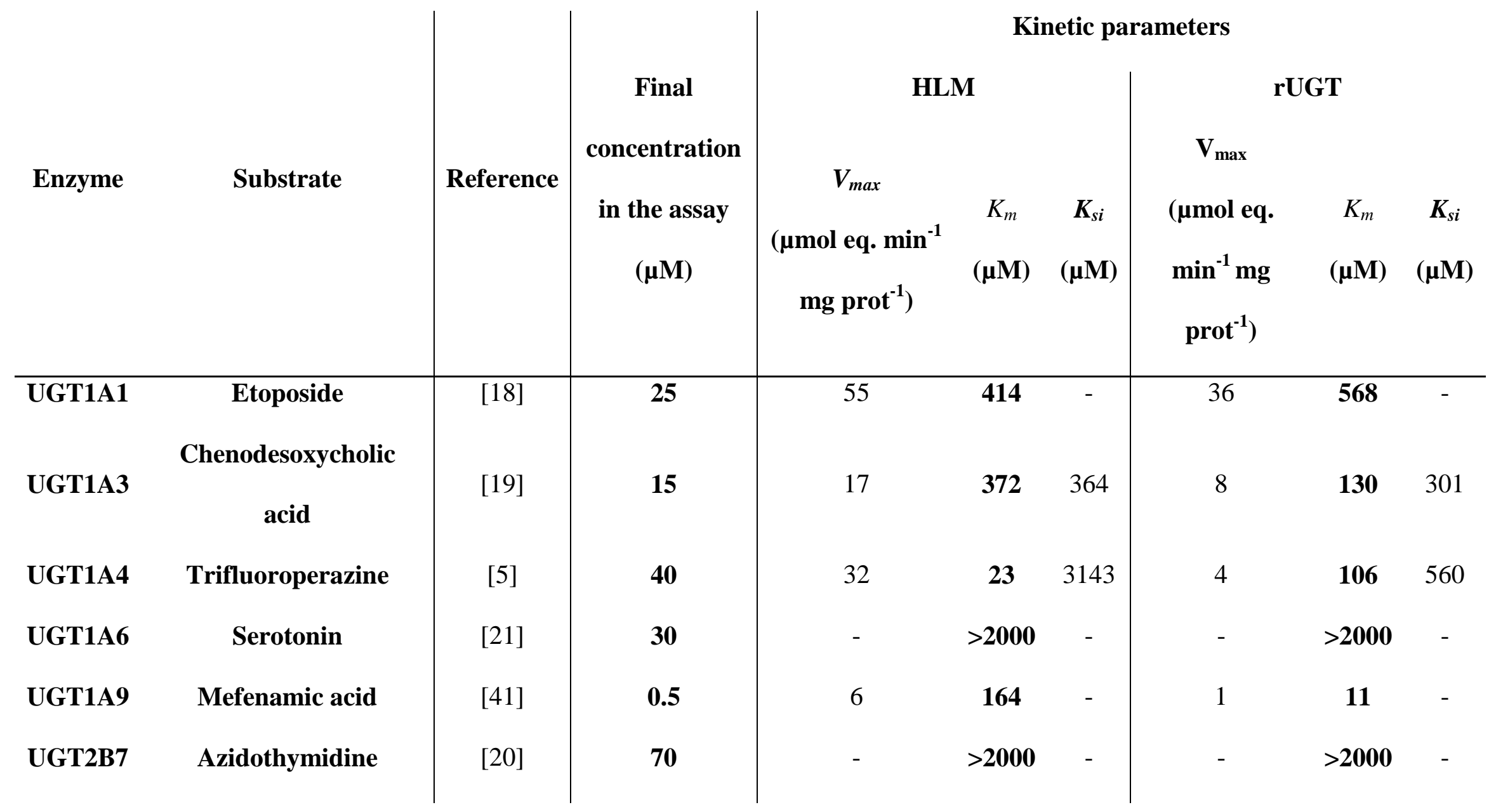


Table 2. LC-MS/MS transitions and retention times of UGT substrates, their respective metabolites and the internal standard (glafenine).

\begin{tabular}{|c|c|c|c|c|}
\hline Analyte & $\begin{array}{c}\text { Transition } 1 \\
(\mathbf{m} / \mathbf{z})\end{array}$ & $\begin{array}{c}\text { Transition } 2 \\
(\mathbf{m} / \mathbf{z})\end{array}$ & $\begin{array}{c}\text { Transition } 3 \\
(\mathbf{m} / \mathbf{z})\end{array}$ & $\begin{array}{c}\text { Retention time } \\
\text { (min) }\end{array}$ \\
\hline Azidothymidine & $268 \rightarrow 127$ & $268 \rightarrow 110$ & & 9.7 \\
\hline $\begin{array}{l}\text { Azidothymidine- } \\
\text { glucuronide }\end{array}$ & $444 \rightarrow 268$ & $444 \rightarrow 127$ & $444 \rightarrow 110$ & 9.3 \\
\hline Chenodeoxycholic acid & $393 \rightarrow 357$ & $393 \rightarrow 81$ & & 16.3 \\
\hline $\begin{array}{c}\text { Chenodeoxycholic acid- } \\
\text { glucuronide }\end{array}$ & $569 \rightarrow 551$ & $569 \rightarrow 357$ & $569 \rightarrow 313$ & 15.1 \\
\hline Etoposide & $606 \rightarrow 209$ & $590 \rightarrow 229$ & & 10.3 \\
\hline Etoposide-glucuronide & $782 \rightarrow 229$ & $782 \rightarrow 185$ & $766 \rightarrow 185$ & 9.8 \\
\hline Mefenamic acid & $242 \rightarrow 180$ & $242 \rightarrow 209$ & & 14.8 \\
\hline $\begin{array}{l}\text { Mefenamic acid- } \\
\text { glucuronide }\end{array}$ & $418 \rightarrow 242$ & $418 \rightarrow 224$ & $418 \rightarrow 209$ & 13.1 \\
\hline Serotonine & $177 \rightarrow 117$ & $177 \rightarrow 77$ & & 6.9 \\
\hline Serotonine-glucuronide & $353 \rightarrow 177$ & $353 \rightarrow 160$ & $353 \rightarrow 117$ & 6.6 \\
\hline Trifluoperazine & $408 \rightarrow 141$ & $408 \rightarrow 113$ & & 10.4 \\
\hline Trifluoperazine-glucuronide & $584 \rightarrow 408$ & $584 \rightarrow 141$ & $584 \rightarrow 113$ & 11.7 \\
\hline Glafenine & $373 \rightarrow 281$ & $373 \rightarrow 218$ & & 9.2 \\
\hline
\end{tabular}


Table 3. Inter-assay and intra-assay precision (RSD) and accuracy -mean relative error (MRE)- of the LC-MS/MS method. Results are derived from 5 independent experiments.

\begin{tabular}{|c|c|c|c|c|c|}
\hline \multirow[b]{2}{*}{ Substrate } & \multirow[b]{2}{*}{$\begin{array}{l}\text { Concentration } \\
\text { range }(\boldsymbol{\mu M})\end{array}$} & \multicolumn{2}{|c|}{ Inter-assay } & \multicolumn{2}{|c|}{ Intra-assay } \\
\hline & & $\begin{array}{c}\text { MRE (\%) } \\
\text { min to } \\
\max \end{array}$ & $\begin{array}{l}\text { RSD (\%) } \\
\text { min to } \\
\max \end{array}$ & $\begin{array}{l}\text { MRE } \\
(\%) \\
\text { min to } \\
\text { max }\end{array}$ & $\begin{array}{l}\text { RSD } \\
(\%) \\
\text { min to } \\
\text { max }\end{array}$ \\
\hline Azidothymidine & $5 \rightarrow 5,000$ & $-8.3 / 18.9$ & $1.8 / 7.5$ & $-10.2 / 12.0$ & $0.5 / 10.4$ \\
\hline $\begin{array}{c}\text { Chenodeoxycholic } \\
\text { acid }\end{array}$ & $50 \rightarrow 5,000$ & $-8.7 / 7.1$ & $2.7 / 8.6$ & $-7.5 / 10.3$ & $1.2 / 8.4$ \\
\hline Etoposide & $10 \rightarrow 5,000$ & $-8.5 / 17.0$ & $4.1 / 7.1$ & $-14.3 / 14.0$ & $1.8 / 16.0$ \\
\hline Mefenamic acid & $25 \rightarrow 1,000$ & $-8.9 / 10.4$ & $2.1 / 7.1$ & $-14.0 / 16.5$ & $1.9 / 4.5$ \\
\hline Serotonine & $10 \rightarrow 5,000$ & $-10.4 / 14.6$ & $2.9 / 6.5$ & $-7.0 / 11.6$ & $0.7 / 7.3$ \\
\hline Trifluoperazine & $10 \rightarrow 1,000$ & $-2.6 / 18.9$ & $2.6 / 7.1$ & $-8.6 / 10.4$ & $1.7 / 11.8$ \\
\hline
\end{tabular}


Table 4. short-term $\left(6 \mathrm{~h}\right.$ at $+4^{\circ} \mathrm{C}$ and $24 \mathrm{~h}$ at $\left.-20^{\circ} \mathrm{C}\right)$, freeze-thaw and auto-sampler stabilities of the glucuronides (Results are derived from $n=3$ incubations with pooled human liver microsomes).

\begin{tabular}{|c|c|c|c|c|}
\hline & $6 \mathrm{~h}\left(+4^{\circ} \mathrm{C}\right)$ & $24 \mathrm{~h}\left(-20^{\circ} \mathrm{C}\right)$ & $\begin{array}{c}\text { freeze-thaw } \\
\text { cycles }\end{array}$ & Auto-sampler \\
\hline controls (Min, Max) & $-6 \% \quad 14 \%$ & $-14 \% \quad 16 \%$ & $-15 \%$ & $-16 \%$ \\
\hline
\end{tabular}

